venous part of the story. Unimaged arterial air may have led to a small but strategic lacunar lesion (e.g., in the internal capsule) that was not visualized on diffusion-weighted MRI.

Author Response: Andrew J. Westwood, Thanh N. Nguyen, Boston: Coebergh et al. agree that the most plausible mechanism for air in the cavernous sinus is a retrograde venous embolism. In reviewing our article, we concur that the discussion may be misleading; we used the term TIA to denote a clinical syndrome which resolved within 1 hour rather than to referring to a proposed mechanism.

We know that the patient was sitting upright at the time. Because air is less dense than blood, it is possible that the embolism traveled retrogradely to produce the transient symptoms. On review of the catheter placement seen on chest x-ray at time of admission, the line appears to be placed with the tip in the superior vena cava. We refer to a study ${ }^{2}$ that monitored paradoxical emboli in patients with transatrial shunts after central line placements. The head CT shows presence of air in the sinus and makes it more likely that it was retrograde. However, paradoxical air embolism should always be considered in patients with transatrial shunts. We thank Coebergh et al. for raising this important issue.

Copyright (C) 2012 by AAN Enterprises, Inc.

1. Westwood AJ, Nguyen TN. Teaching NeuroImages: TIA from an air embolism. Neurology 2011;77:123.

2. Engelhardt M, Folkers W, Brenke C, et al. Neurosurgical operations with the patient in sitting position: analysis of risk factors using transcranial Doppler sonography. $\mathrm{Br} \mathrm{J}$ Anaesth 2006;96:467-472

\section{ACUTE MYELOID LEUKEMIA IN ITALIAN PATIENTS WITH MULTIPLE SCLEROSIS TREATED WITH MITOXANTRONE}

Anke Stroet, Ralf Gold, Andrew Chan, Bochum, Germany: Martinelli et al. ${ }^{1}$ reported a relatively large incidence of therapy-related acute myeloid leukemia (TRAL) in a retrospective Italian MS cohort $(0.93 \%)$. In contrast, we observed a much lower TRAL incidence in a large retrospective German cohort (range of $0.25 \%$ to $0.41 \%)^{2}$ similar to 2 prospective studies, ${ }^{3,4}$ despite observation intervals comparable to Martinelli et al. In addition to methodologic aspects, differences may also relate to other factors including pretreatment and treatment protocols.

A 3-month treatment regimen is common in Germany, as demonstrated in one pivotal phase III trial $^{5}$; $68.9 \%$ of the Italian patients were treated bimonthly or monthly. In addition, dose adjustment-according to leukocyte nadir-is not described in the Italian study but is required per the Summary of Product Characteristics in Germany. It is conceivable that higher dosages over a shorter time may pose an increased risk for toxicity. Potentially additive or genotoxic cotreatment further complicates data analysis. Besides the introduction of uniform treatment algorithms, larger collaborative studies should focus on potential risk factors as well as individual predisposition, e.g., pharmacogenomic characteristics.

This is important since treatment alternatives are still sparse in rapidly progressing secondary progressive MS.

\section{Author Response: Vittorio Martinelli, Laura} Straffi, Giancarlo Comi, Milan, Italy: We agree that there is variability in TRAL incidence in patients with MS. We observed this in our multicenter study ${ }^{1}$ where TRAL incidence among centers ranged from $0 / 167$ to $4 / 115$. It is also recognized that published single cohort studies may be more biased toward high incidence than unpublished data.

Our data contradict other studies ${ }^{2-4}$ with similar observational follow-up, but there were methodologic differences, including sample size $\left(3,220^{1}\right.$ vs $1,156^{2}$ or $802^{3}$ ); follow-up of at least 1 year; and the closely linked network of Italian centers. Furthermore, 2 new acute myeloid leukemia cases were confirmed in the last year in our original cohort.

As Chan et al. suggest, we suspect that risk might be related to a specific treatment regimen or cotreatment, but we did not find this association. Moreover, monthly ${ }^{3}$ and 3-monthly infusions ${ }^{2}$ appear to have similar incidences. We believe that without a means of identifying susceptibility, ${ }^{6}$ the risk of TRAL must always be considered, perhaps with some type of "regional" stratification. There are currently 106 cases reported worldwide, onethird of which may be fatal.

Copyright (C) 2012 by AAN Enterprises, Inc.

1. Martinelli V, Cocco E, Capra R, et al. Acute myeloid leukemia in Italian patients with multiple sclerosis treated with mitoxantrone. Neurology 2011;77:1887-1895.

2. Stroet A, Starck M, Zettl U, et al. Incidence of therapyrelated acute leukemia in mitoxantrone-treated multiple sclerosis patients in Germany. Ther Adv Neurol Disord (in press 2012)

3. Le Page E, Leray E, Edan G. Long-term safety profile of mitoxantrone in a French cohort of 802 multiple sclerosis 
patients: a 5- year prospective study. Mult Scler 2011;17: 867-875.

4. Rivera V, Weinstock-Guttman B, Beagan J, Al-Sabbagh A, Bennett R, Dangond F. Final results from Registry to Evaluate Novantrone Effects in Worsening Multiple Sclerosis Study (RENEW). Mult Scler 2009;15:S254.
5. Hartung HP, Gonsette R, Konig N, et al. Mitoxantrone in progressive multiple sclerosis: a placebo-controlled, double-blind, randomized, multicenter trial. Lancet 2002;360:2018-2025.

6. Joannides M, Mays AN, Mistry AR, et al. Molecular pathogenesis of secondary acute promyelocytic leukemia. Mediterr J Hematol Infect Dis 2011;3: e2011045.

\section{Commenting Online is Easier Now with WriteClick}

Have a comment on a recent Neurology ${ }^{\circledR}$ article you would like to share? Now it is easier and more convenient. Neurology.org has launched WriteClick on the home page and sidebars of each article to encourage remarks and debate among users.

WriteClick is restricted to comments about studies published in Neurology within the last eight weeks.

Learn more at http://www.neurology.org/letters

Author disclosures are available upon request (journal@neurology.org). 


\section{Neurology}

\section{Acute myeloid leukemia in italian patients with multiple sclerosis treated with mitoxantrone}

Anke Stroet, Vittorio Martinelli, Ralf Gold, et al. Neurology 2012;78;933-934

DOI 10.1212/01.wnl.0000413366.14351.54

\section{This information is current as of March 19, 2012}

\section{Updated Information \&} Services

References

Citations

Permissions \& Licensing

Reprints including high resolution figures, can be found at: http://n.neurology.org/content/78/12/933.full

This article cites 5 articles, 1 of which you can access for free at: http://n.neurology.org/content/78/12/933.full\#ref-list-1

This article has been cited by 1 HighWire-hosted articles: http://n.neurology.org/content/78/12/933.full\#\#otherarticles

Information about reproducing this article in parts (figures,tables) or in its entirety can be found online at:

http://www.neurology.org/about/about_the_journal\#permissions

Information about ordering reprints can be found online:

http://n.neurology.org/subscribers/advertise

Neurology ${ }^{\circledR}$ is the official journal of the American Academy of Neurology. Published continuously since 1951, it is now a weekly with 48 issues per year. Copyright Copyright $@ 2012$ by AAN Enterprises, Inc.. All rights reserved. Print ISSN: 0028-3878. Online ISSN: 1526-632X.

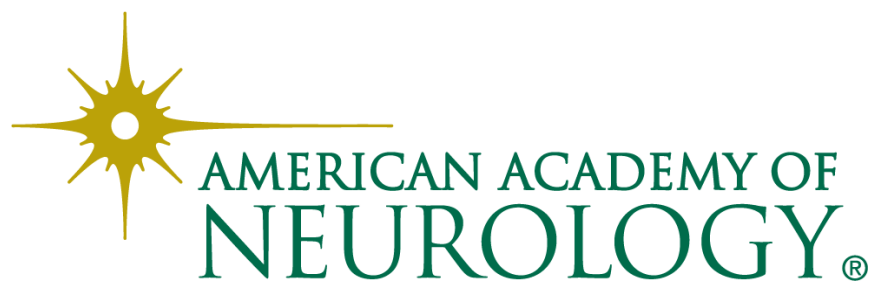

